\title{
Rancang Bangun Mesin Perajang Singkong dengan Pendorong Pegas
}

\author{
Venditias Yudha ${ }^{*}$, Nanang Nugroho ${ }^{2}$ \\ 1Jurusan Teknik Mesin, Fakultas Teknologi Industri, Institut Sains \& Teknologi AKPRIND \\ Yogyakarta \\ 2Teknik dan Bisnis Sepeda Motor, SMK Negeri 1 Wonosegoro, Boyolali \\ *Penulis korespondensi: venditias.y@akprind.ac.id
}

Histori artikel: diserahkan 02 Oktober 2020, direviu 05 Oktober 2020, direvisi 08 Oktober 2020

\begin{abstract}
The home industry business of cassava chips on Jogonalan, Klaten, was using manual tools in the process of slicing raw cassava. The cassava cutting machine was an alternative solution for the businessman to increase productivity in producing cassava chips. Cassava, as a raw material for making chips will be easily cut with this machine. This design aims to plan a cassava cutting machine with a safe and efficient construction in its application. The machine design method refers to the Pahl and Beitz concept. The planning and design process into the following main phases: Planning and task clarification, conceptual design, embodiment design, and detail design. Analysis of the motion mechanism and calculation of engine elements were used to determine the machine's power specification and capacity. The cassava cutting machine's planned capacity is $80 \mathrm{~kg} / \mathrm{hour}$ with a motor power of $0.25 \mathrm{hp}$, the final rotation of $210 \mathrm{rpm}$. The technical analysis result on the main part of the cassava cutting shows that the power capacity of the electric motor, transmission system, and frame construction on the machine was safe.
\end{abstract}

Keywords: Cassava cutting machine, Pahl and Beitz method, spring pusher

DOI: https://doi.org/10.18196/jqt.020118

Web: https://journal.umy.ac.id/index.php/qt/article/view/10027

\section{PENDAHULUAN}

Singkong menjadi salah satu sumber bahan pangan yang tinggi akan kandungan karbohidrat. Menurut Kamsiati et al. (2017), kandungan karbohidrat pada singkong berkisar antara 34,7-37,9\%. Singkong dapat diolah menjadi tepung, makanan tradisional gaplek (Abdullah et al., 2019) dan keripik. Keripik singkong banyak ditemui di daerah Jogonalan, Klaten yang merupakan salah satu sentra industri makanan ringan yang ada di kota Klaten. Singkong sebagai bahan dasar keripik ini diperoleh dari petani singkong di daerah Klaten dan Jawa Tengah. Masyarakat di daerah Klaten dan Jawa tengah masih banyak yang menanam singkong, sehingga untuk memperoleh bahan baku produksi masih relatif mudah.

Produsen dalam memproduksi keripik singkong melalui beberapa tahapan, salah satunya adalah proses perajangan singkong. Perajangan ini dilakukan agar singkong berbentuk tipis dengan memiliki tebal tertentu, sehingga menjadikan singkong renyah ketika digoreng. Selama ini masih banyak produsen keripik singkong skala home industry di Klaten merajang singkong dengan alat perajang yang sederhana atau secara manual seperti ditunjukkan pada Gambar 1.

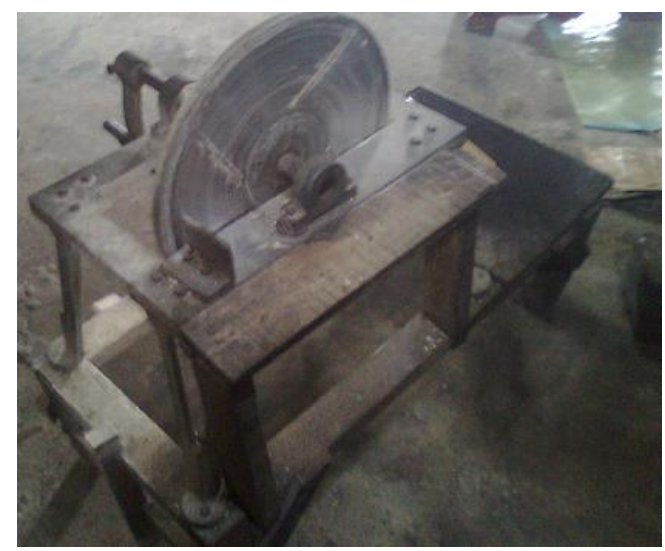

GAMBAR 1. Alat perajang singkong milik salah satu produsen keripik di Klaten 
Setiap harinya produsen keripik singkong di Klaten memproduksi keripik kurang lebih sebanyak $150 \mathrm{~kg}$. Namun, kapasitas perajangan menggunakan alat tersebut hanya mampu menghasilkan $19 \mathrm{~kg} / \mathrm{jam}$. Hal itu dikarenakan alat perajang singkong berpenggerak manual, belum memiliki casing, dan proses memasukkan singkong dipengang dengan tangan.

Berdasarkan masalah yang dihadapi produsen keripik singkong di Klaten, maka dibuat alternatif solusi dengan merancang dan modifikasi mesin perajang singkong semi otomatis dengan pendorong pegas. Dengan mesin ini diharapkan mampu menjadi solusi bagi produsen keripik untuk meningkatkan produktivitas usahanya.

\section{METODE PERANCANGAN}

Proses perancangan mesin perajang singkong mengacu pada metode perancangan Pahl dan Beitz (2007), terdiri dari empat tahap utama, yaitu: perencanaan dan penjelasan tugas, perencanaan konsep produk, perencanaan produk, dan perencanaan detail. Tahapan perancangan yang baik diharapkan mampu menghasilkan produk perancangan mesing yang optimal sesuai dengan spesifikasi yang diharapkan. Konsep perancangan dibuat berdasarkan analisis kebutuhan dari produk tersebut (Sokhibi et al., 2019), seperti ditunjukkan pada Tabel 1.

TABEL 1. Analisis kebutuhan produk

\begin{tabular}{ccl}
\hline \multicolumn{3}{c}{ Analisis kebutuhan produk } \\
\hline No. & $\mathrm{S} / \mathrm{H}$ & Uraian kebutuhan \\
\hline 1 & $\mathrm{~S}$ & Kapasitas $80 \mathrm{~kg} / \mathrm{jam}$ \\
\hline 2 & $\mathrm{~S}$ & Berpenggerak motor listrik \\
\hline 3 & $\mathrm{~S}$ & Mudah dalam pengoperasian \\
\hline 4 & $\mathrm{~S}$ & Mudah dalam perawatan \\
\hline 5 & $\mathrm{~S}$ & Kontruksi kuat dan aman \\
\hline 6 & $\mathrm{H}$ & Mudah dibongkar pasang \\
\hline 7 & $\mathrm{H}$ & Proses perajangan semi otomatis \\
\hline 8 & $\mathrm{H}$ & Komponen mudah didapat
\end{tabular}

Keterangan: $\mathrm{S}=$ Syarat

$$
\mathrm{H}=\text { Harapan }
$$

Setelah menentukan kebutuhan produk, selanjutnya melakukan perencanaan konsep pengembangan produk berdasarakan alternatif konsep dari referensi mesin sejenis yang telah dibuat dan spesifikasi mesin yang akan dibuat.

Setelah mendapatkan konsep rancangan mesin perajang singkong, selanjutnya dibuat gambar mesin secara detail dengan tujuan untuk mengkomunikasikan pada tahapan selanjutnya yaitu proses manufaktur dan perakitan. Pembuatan gambar dilakukan menggunakan software Autodesk Inventor Professional 2012. Analisis teknik berupa perhitungan terhadap elemen-elemen mesin dilakukan berdasarkan konsep perencanaan mesin yang telah ditentukan. Tujuannya adalah untuk menentukan kelayakan perancangan atau identifikasi kelemahan hasil perancangan. Hasil evaluasi dilanjutkan sebagai bahan kajian pengembangan produk selanjutnya atau sebagai langkah penyempurnaan mesin. Konsep rancangan mesin perajang singkong dengan pendorong pegas dapat dilihat pada Gambar 2.

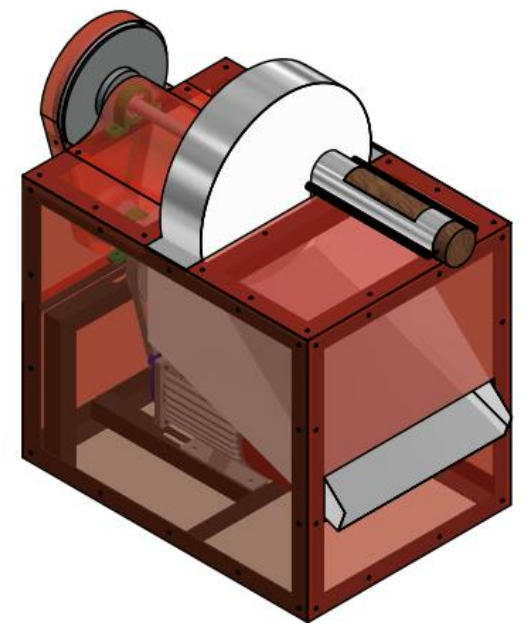

GAMBAR 2. Desain perencanaan mesin perajang singkong degan pendorong pegas

\section{HASIL DAN PEMBAHASAN}

\section{Hasil rancangan mesin perajang singkong}

Rancangan mesin perajang singkong ini didasarkan pada kebutuhan home industry di daerah Jogonalan, Klaten untuk meningkatkan produktifitas, efektifitas dan nilai ekonomi para produsen kripik singkong. Mesin ini merupakan hasil modifikasi dari alat perajang singkong yang sudah ada, dan merupakan 
sebuah alternalif solusi bagi produsen keripik singkong dalam melakukan perajangan secara efisien. Tabel 2 merupakan tahapan yang dilakukan dalam perancangan mesin perajang singkong dengan mengacu pada motode Pahl dan Beizt:

TABEL 2. Varian kegiatan perancangan mesin

\begin{tabular}{|c|c|}
\hline Tahapan & Aktivitas \\
\hline $\begin{array}{l}\text { 1. Perencanaan } \\
\text { dan penjelasan } \\
\text { tugas } \\
\text { (Planning and } \\
\text { task } \\
\text { clarification) }\end{array}$ & $\begin{array}{l}\text { 1.1. Mesin menggunakan } \\
\text { penggerak motor listrik } \\
\text { 1.2. Dimensi mesin sedang } \\
\text { 1.3. Kapasitas produksi yang } \\
\text { diharapkan } 80 \mathrm{~kg} / \mathrm{jam} \\
\text { 1.4. Pendorong singkong } \\
\text { dibuat semi otmatis }\end{array}$ \\
\hline $\begin{array}{ll}\text { 2. } & \text { Konsep } \\
\text { produk } \\
\text { (Conceptual } \\
\text { design) }\end{array}$ & $\begin{array}{l}\text { 2.1. Dimensi mesin } \\
\text { ergonomis } \\
\text { 2.2. Sistem transmisi } \\
\text { menggunakan } \\
\text { perbandingan pulley } \\
\text { 2.3. Bagian ujung pisau } \\
\text { dibuat radius } \\
\text { 2.4. Sistem pendorong } \\
\text { singkong menggunakan } \\
\text { pegas } \\
\text { 2.5. Saluran keluar dari bahan } \\
\text { stainless steel } \\
\text { 2.6. Komponen-komponen } \\
\text { mudah didapatkan }\end{array}$ \\
\hline $\begin{array}{l}\text { 3. Perencanaan } \\
\text { produk } \\
\text { (Embodiment } \\
\text { design) }\end{array}$ & $\begin{array}{l}\text { 3.1. Membuat daftar } \\
\text { komponen } \\
\text { 3.2. Membuat sket awal dari } \\
\text { konsep perancangan } \\
\text { mesin perajang singkong } \\
\text { 3.3. Membuat layout awal } \\
\text { semua komponen } \\
\text { 3.4. Mengkaji layout dengan } \\
\text { pertimbangan fungsi dan } \\
\text { pemilihan bahan. } \\
\text { 3.5. Mengkaji keterserdiaan } \\
\text { komponen suku cadang }\end{array}$ \\
\hline $\begin{array}{l}\text { 4. Detail produk } \\
\text { (Detail } \\
\text { design) }\end{array}$ & $\begin{array}{l}\text { 4.1. Menyiapkan layout awal } \\
\text { yang telah dikaji dan } \\
\text { melengkapi daftar detail } \\
\text { 4.2. Memeriksa kembali } \\
\text { layout awal yang telah } \\
\text { dikaji menjadi gambar } \\
\text { kerja } \\
\text { 4.3. Menggunakan layout } \\
\text { akhir yang digunakan } \\
\text { sebagai pedoman proses } \\
\text { produksi }\end{array}$ \\
\hline
\end{tabular}

Hasil dari perancangan konsep produk berupa list komponen-komponen yang digunakan dalam perencanaan mesin perajang singkong yang disajikan pada Tabel 3 .

TABEL 3. Varian yang digunakan untuk Mesin perajang singkong

\begin{tabular}{|c|c|c|}
\hline No. & Bagian & Varian yang dipilih \\
\hline 1. & $\begin{array}{l}\text { Tenaga } \\
\text { penggerak }\end{array}$ & Motor listrik \\
\hline 2. & $\begin{array}{l}\text { Sistem } \\
\text { transmisi }\end{array}$ & pulley \\
\hline 3. & $\begin{array}{l}\text { Sistem putaran } \\
\text { pisau }\end{array}$ & $\prod_{\text {Pisau berputar vertical }}^{\mid}$ \\
\hline 4. & Profil rangka & Besi Siku 40x40x3mm \\
\hline 5. & Bahan casing & $\begin{array}{l}\text { Kombinasi Plat eyser } \\
\text { dan Plat stainless steel }\end{array}$ \\
\hline 6. & Penahan poros & Pillow block bearing \\
\hline 7. & Pisau perajang & $\begin{array}{l}\text { Pisau dengan ujung } \\
\text { radius }\end{array}$ \\
\hline 8. & Bahan pisau & Stainless steel \\
\hline 9. & $\begin{array}{l}\text { Bentuk saluran } \\
\text { masuk }\end{array}$ & Silinder \\
\hline 10. & $\begin{array}{l}\text { Pendorong } \\
\text { singkong }\end{array}$ & Pegas \\
\hline 11. & Poros & Mild steel \\
\hline
\end{tabular}

Gambar 3 menunjukkan detail komponen yang telah dirakit menjadi suatu mesin perajang singkong. Modifikasi dilakukan pada proses perajangan di saluran masuk, yaitu singkong didorong menggunakan sistem pegas. 


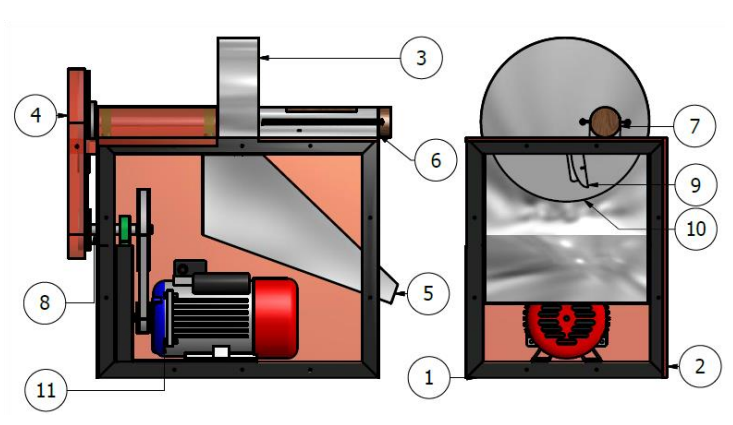

GAMBAR 3. Komponen pada mesin perajang singkong dengan pendorong pegas

Keterangan Gambar 3:
1. Rangka
2. Casing
3. Casing penutup
7. Pendorong
piringan
4. Casing penutup pulley
8. Poros transmisi
9. Pisau
10. Piringan pisau

5. Saluran keluar

6. Saluran masuk
11. Motor listrik

\section{Analisis teknik}

\section{Gaya potong singkong}

Gaya potong singkong merupakan suatu gaya yang yang harus diketahui untuk memulai perencanaan alat perajang singkong. Untuk memperoleh gaya potong singkong dapat menggunakan percobaan pembebanan seperti ditunjukkan pada Gambar 4.

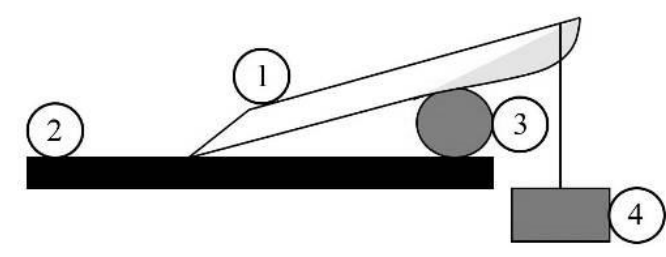

GAMBAR 4. Skematik analisa gaya potong singkong

Keterangan gambar 4:

1. Pisau perajang

2. Landasan perajang

3. Singkong

4. Beban

Hasil percobaan pembebanan ditunjukkan pada tabel 4 .

TABEL 4. Hasil analisa gaya potong singkong

\begin{tabular}{ccc}
\hline Percobaan & Ukuran $(\mathrm{mm})$ & Beban $(\mathrm{kg})$ \\
\hline 1 & $\varnothing 36$ & 3,4 \\
\hline 2 & $\varnothing 40$ & 3,8 \\
\hline 3 & $\varnothing 46$ & 4,6 \\
\hline 4 & $\varnothing 49$ & 5 \\
\hline 5 & $\varnothing 54$ & 6 \\
\hline
\end{tabular}

Dari hasil percobaan tersebut menunjukkan bahwa beban pemotongan maksimal yang dapat digunakan untuk merajang singkong adalah $6 \mathrm{~kg}$. Beban ini merupakan gaya potong singkong yang nantinya akan digunakan dalam perhitungan selanjutnya.

\section{Perencanaan putaran mesin}

Perencanaan putaran mesin adalah banyaknya putaran yang direncanakan untuk melakukan 1 $\mathrm{kg}$ perajangan singkong. Karena pisau yang digunakan adalah empat buah maka berat potongan dalam sekali putar adalah:

Berat $=4 \mathrm{x}$ berat setiap potongan singkong, sehingga besar putaran per kg adalah:

$$
\mathrm{N}=(1000 \text { gr }) / \text { Berat }
$$

Hasil percobaan pembebanan ditunjukkan pada Tabel 5.

TABEL 5. Hasil Analisa gaya potong singkong

\begin{tabular}{ccc}
\hline Percobaan & Ukuran (mm) & Berat (gr) \\
\hline 1 & $\varnothing 31 \times 1$ & 3,4 \\
\hline 2 & $\varnothing 40 \times 1$ & 3,8 \\
\hline 3 & $\varnothing 34 \times 2$ & 4,6 \\
\hline \multicolumn{3}{c}{ Rata-rata } \\
\hline
\end{tabular}

Berat singkong yang dihasilkan setiap putaran: Berat $=4 \times 1,58 \mathrm{gr}=6,32 \mathrm{gr}$

Besarnya putaran yang diperlukan per kilogram:

$$
\begin{aligned}
& N=1000 \text { gr/Berat } \\
& N=1000 / 6,32 \\
& N=158,23 \text { putaran } \approx 159 \text { putaran }
\end{aligned}
$$

Kapasitas yang direncanakan adalah 80 $\mathrm{kg} / \mathrm{jam}$, sehingga putaran yang diperlukan adalah:

$$
\begin{aligned}
& n=\frac{(\text { kapasitas })(\text { putaran) }}{1 \mathrm{~kg}} \\
& n=\frac{(80 \mathrm{~kg} / \mathrm{jam})(159 \text { putaran })}{1 \mathrm{~kg}}
\end{aligned}
$$




$$
\begin{aligned}
& n=\frac{(1,32 \mathrm{~kg} / \text { menit })(159 \text { putaran })}{1 \mathrm{~kg}} \\
& n=209,88 \mathrm{rpm} \approx 210 \mathrm{rpm}
\end{aligned}
$$

Putaran yang dibutuhkan mesin berdasarkan hasil perhitungan tersebut adalah $210 \mathrm{rpm}$.

\section{Perencanaan daya gerak}

Gaya pada pisau

$$
\begin{aligned}
\mathrm{F} & =\mathrm{m} \cdot \mathrm{g} \\
\mathrm{F} & =6 \mathrm{~kg} .9,8 \mathrm{~m} / \mathrm{s} \\
\mathrm{F} & =58,8 \mathrm{~N}
\end{aligned}
$$

Torsi pada pisau perajang alat perajang singkong dengan gaya potong $6 \mathrm{~kg}$, dengan jarak pisau dari pusat piringan $100 \mathrm{~mm}$, yaitu:

$$
\begin{aligned}
\mathrm{T} & =\mathrm{F} \times \mathrm{r} \\
& =58,8 \mathrm{~N} .0,1 \mathrm{~m} \\
& =5,88 \mathrm{~N} / \mathrm{m}
\end{aligned}
$$

Daya yang dibutuhkan untuk menggerakkan pisau:

$$
\begin{aligned}
& P=\frac{2 \pi n T}{60} \\
& P=\frac{2 \times 3,14 \times 210 \times 5,88}{60} \\
& P=129,24 \text { watt }=0,173 \mathrm{hp}
\end{aligned}
$$

Berdasarkan hasil perhitungan diatas, diketahui daya motor $0,25 \mathrm{hp}$, disesuaikan dengan yang ada di pasaran. Spesifikasi motor listrik yang digunakan yaitu: $\mathrm{n}=1400 \mathrm{rpm} ; \mathrm{P}=0,25 \mathrm{hp}$; tegangan $=110 / 220 \mathrm{~V}$

\section{Perencanaan sistem transmisi}

Sistem transmisi terdiri dari beberapa komponen yaitu puli, v-belt, poros, dan motor listrik. Sistem transmisi bertujuan untuk meneruskan daya dan mengubah kecepatan motor listrik dari $1400 \mathrm{rpm}$ menjadi $210 \mathrm{rpm}$. Rancangan v-belt ditunjukkan pada Gambar 5.

Penampang $v$-belt yang digunakan adalah tipe A

dengan diameter pulley:

$\mathrm{D}_{1}=76,2 \mathrm{~mm} ; \mathrm{D}_{2}=203,2 \mathrm{~mm}$

$\mathrm{D}_{3}=101,6 \mathrm{~mm} ; \mathrm{D}_{4}=254 \mathrm{~mm}$

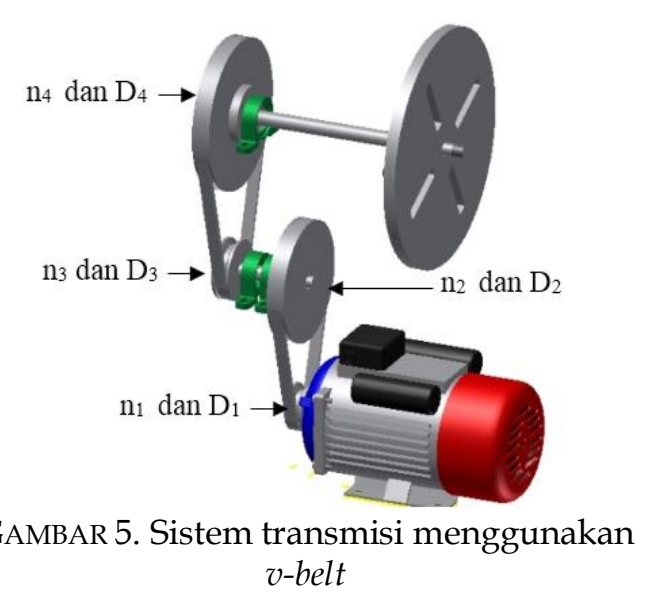

$V$-belt terbuat dari bahan karet dan mempunyai penampang trapesium. $v$-belt dibelitkan di keliling alur pulley yang berpenampang $\mathrm{V}$ juga. Panjang keliling sabuk dan jarak sumbu poros ditunjukkan pada Gambar 6.

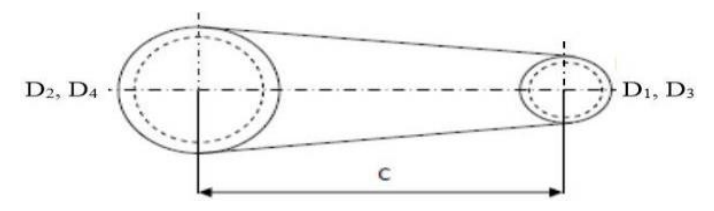

$\mathrm{D}_{1}, \mathrm{D}_{3}=$ diameter luar pulley penggerak

Panjang keliling sabuk dicari menggunakan rumus berikut:

$$
L_{1}=2 \mathrm{C}+\frac{\pi}{2}\left(\mathrm{D}_{\mathrm{P}}+\mathrm{D}_{D}\right)+\frac{1}{4 \mathrm{C}}\left(\mathrm{D}_{\mathrm{D}}-\mathrm{D}_{\mathrm{P}}\right)^{2}
$$

dengan $\mathrm{C}=225 \mathrm{~mm}, \mathrm{D}_{\mathrm{P}}=$ diameter pulley penggerak $(\mathrm{mm}), \mathrm{D}_{\mathrm{D}}=$ diameter pulley yang digerakkan (mm).

Panjang keliling sabuk untuk pulley 1 dan pulley 2 yaitu:

$$
\begin{aligned}
& L_{1}=2.225+\frac{\pi}{2}(76,2+203,2)+\frac{1}{4.225}(203,2-76,2)^{2} \\
& L_{1}=906,58 \mathrm{~mm}
\end{aligned}
$$

Panjang keliling sabuk untuk pulley 3 dan pulley 4 yaitu:

$$
\begin{aligned}
& L_{2}=2.255+\frac{\pi}{2}(101,6+254)+\frac{1}{4.255}(254-101,6)^{2} \\
& L_{2}=1091,06 \mathrm{~mm}
\end{aligned}
$$

Jadi v-belt yang digunakan adalah tipe A-36, $(\mathrm{L}=914 \mathrm{~mm})$, dan tipe A-43, $(\mathrm{L}=1092 \mathrm{~mm})$, karena $\mathrm{L}$ sabuk mendekati $\mathrm{L}_{1}(906,58 \mathrm{~mm})$ dan $\mathrm{L}_{2}(1091,06 \mathrm{~mm})$ perencanaan. 


\section{Analisis rangka}

Dimensi mesin yaitu memiliki panjang 500 $\mathrm{mm}$, lebar $700 \mathrm{~mm}$ dan tinggi $600 \mathrm{~mm}$. Analisa pembebanan pada rangka mesin menggunakan software Autodesk Inventor Professional 2012. Struktur rangka mesin perajang singkong yang dianalisis ditunjukkan pada Gambar 7.

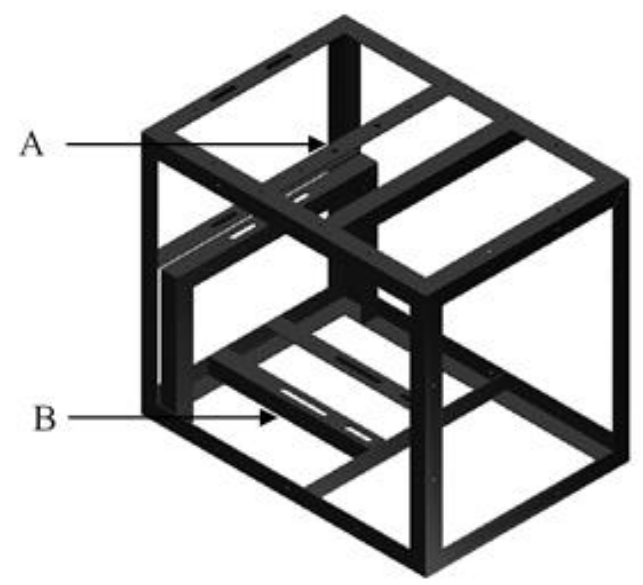

GAMBAR 7. Kontruksi rangka mesin

Gaya yang bekerja pada rangka alat perajang singkong ini merupakan hasil pembebanan dari beberapa komponen yang ada pada alat. Pada rangka yang ditunjukkan oleh huruf A menerima beban poros sedangkan yang ditunjukkan oleh huruf B merupakan dudukan motor listrik.

Defleksi pada batang A ditunjukkan oleh Gambar 8 berikut:

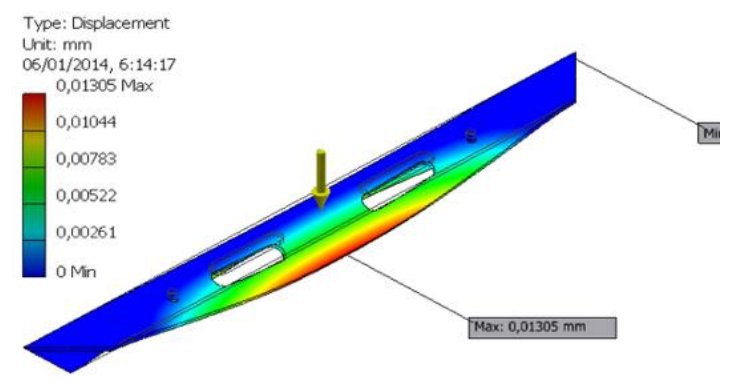

GAMBAR 8. Defleksi pada batang A

Defleksi yang diijinkan yaitu antara 0,0005 sampai dengan $0,003 \mathrm{in} /$ in panjang batang atau 0,0127 sampai dengan $0,0762 \mathrm{~mm} / \mathrm{mm}$ panjang batang (Mott, 2009:113). Hasil analisis menunjukkan konstruksi rangka dalam keadaan aman. Defleksi yang terjadi pada rangka $(0,0130 \mathrm{~mm})<$ defleksi yang diijinkan $(0,0762 \mathrm{~mm})$ sehingga rangka dapat disimpulkan aman.
Defleksi pada batang B ditunjukkan oleh Gambar 9 berikut:

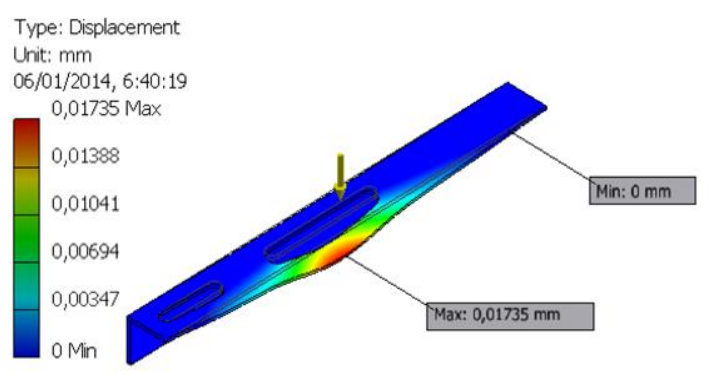

GAMBAR 9. Defleksi pada batang B

Hasil analisis menunjukkan konstruksi rangka dalam keadaan aman. Defleksi yang terjadi pada rangka $(0,0173 \mathrm{~mm})<$ defleksi yang diijinkan $(0,0762)$ sehingga kontruksi rangka dapat disimpulkan aman.

\section{Proses Fabrikasi}

Proses fabrikasi mesin perajang singkong dengan pendorong pegas dilakukan berdasarkan detail gambar yang telah dibuat pada proses perancangan. Dari hasil perancangan mesin, diketahui ada beberapa komponen dibeli dan komponen yang di manufaktur. Adapapun komponen yang dibeli yaitu motor listrik, pisau potong, pillow block bearing, pegas, serta mur dan baut, Jenis proses manufaktur pada tiap komponen mesin dijelaskan pada tabel 6. Komponen-komponen tersebut kemudian di rakit menjadi suatu sistem mekanik yaitu mesin perajang singkong dengan pendorong pegas, seperti ditunjukkan pada Gambar 10.

TABEL 6. Jenis proses manufaktur pada komponen mesin

\begin{tabular}{ll}
\hline Komponen & \multicolumn{1}{c}{ Jenis proses } \\
\hline \multirow{3}{*}{ Rangka mesin } & - Proses gerinda \\
& - Proses gurdi \\
& - Proses frais \\
& - Proses las listrik \\
\hline \multirow{2}{*}{ Poros } & - Proses gergaji \\
& - Proses bubut \\
& - Proses frais \\
\hline \multirow{2}{*}{ Piringan pisau } & - Proses gerinda \\
& - Proses frais \\
\hline \multirow{2}{*}{ Casing mesin } & - Proses gurdi \\
\hline
\end{tabular}




\begin{tabular}{ll}
\hline $\begin{array}{l}\text { Pendorong } \\
\text { singkong }\end{array}$ & - Proses bubut \\
\hline Saluran masuk dan & - Proses gurdi \\
saluran keluar & - Proses penekukan plat \\
\hline
\end{tabular}

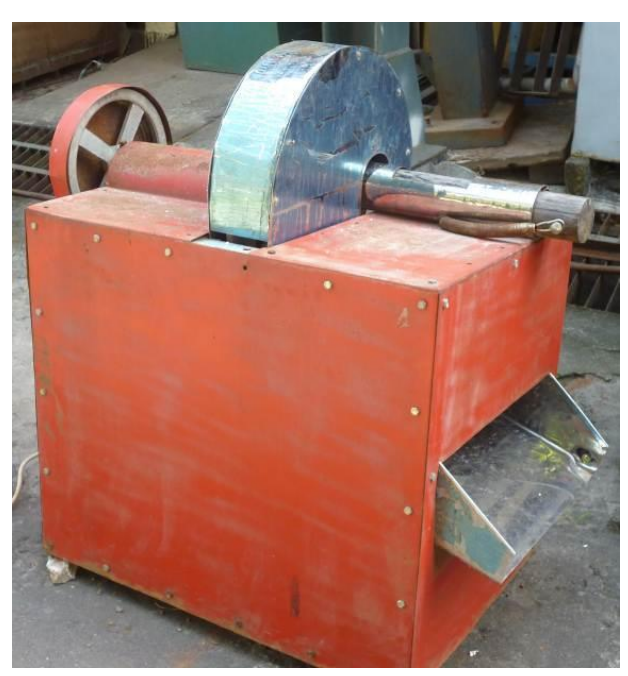

GAMBAR 10. Mesin perajang singkong dengan pendorong pegas

\section{KESIMPULAN}

Hasil perancangan mesin perajang singkong memiliki dimensi yang ergonomis. Pengoperasian mesin mudah dan hanya membutuhkan tenaga satu orang operator. Kapasitas perajangan singkong mencapai 80 $\mathrm{kg} / \mathrm{jam}$ dengan pendorong singkong semi otomatis menggunakan pegas. Daya motor listrik menggunakan $0,25 \mathrm{hp}$ dengan putaran motor $1400 \mathrm{rpm}$ dan putaran akhir pada piringan pisau $210 \mathrm{rpm}$. Sistem transmisi mengggunakan v-belt tipe A-34 dan A-43. Hasil analisa struktur pada mesin menunjukkan bahwa rangka dalam keadaan aman.

\section{DAFTAR PUSTAKA}

Abdullah, K., \& Jyoti, M. D. 2019. Kajian Hilirisasi Industri Berbasis Singkong dalam Industri Pangan. Majalah TEGI, 11(2), 44-53.

Kamsiati, E., Herawati, H., \& Purwani, E. Y. 2017. Potensi pengembangan plastik biodegradable berbasis pati sagu dan ubikayu di indonesia. Jurnal Penelitian dan Pengembangan Pertanian, 36(2), 67-76..
Mott, R. L. 2009. Elemen-Elemen Mesin Dalam Perancangan Mekanis. Yogyakarta: Penerbit ANDI

Pahl G., and Beitz, W. 2007. Engineering Design: A Systematic Approach. London: Springer-Verlag GmbH.

Sularso dan Suga, Kiyokatsu. 2002. Dasar Perencanaan dan Pemilihan Elemen Mesin. Jakarta: Pradnya Paramita.

Sokhibi, A. and Rachmawati, P., 2019. Perancangan Kursi Untuk Memperbaiki Posisi Kerja Guna Meningkatkan Produktivitas Studi Kasus Di PG Jatibarang Brebes. Quantum Teknika: Jurnal Teknik Mesin Terapan, 1(1), pp.39-47. 